\title{
Televisão em Contexto Português: a estória de uma história ${ }^{1}$
}

\author{
Portuguese television system: an historical approach
}

\author{
Filomena Antunes Sobral ${ }^{2}$ \\ Instituto Politécnico de Viseu/ \\ Universidade Católica Portuguesa - E. Artes/ CITAR
}

\begin{abstract}
Resumo:
Inserida numa conjuntura de convergência dos média e de transformação tecnológica, a televisão generalista em Portugal procura adaptar-se à contemporaneidade numa perspectiva de desenvolvimento e modernização. Apesar de conviver com novos meios de difusão e diferentes formas de consumo, a televisão não perde a sua importância, tendo, no entanto, que ajustar-se a outros modelos de utilização. Procuramos neste artigo estabelecer um quadro histórico de evolução da televisão em Portugal, numa dupla abordagem de caracterização do sistema televisual vigente e de perspectivar o futuro que se adivinha.
\end{abstract}

Palavras-chave: Televisão, história, programação, Portugal.

\begin{abstract}
:
Inserted within the combination of events between the convergence of the media and of technological transformation, generalist television in Portugal aims to adapt itself to contemporaneity from the perspective of development and modernization.

Although familiar with new means of diffusion and also with different ways of consumption, television does not lose its importance; however, it does have to adjust itself to other models of use.

It is the objective of this paper to try to establish an historical picture of the evolution of television in Portugal taking into account the characterization of the televisual system in order to put the future into perspective.
\end{abstract}

Keywords: television, history, programme, Portugal.

\footnotetext{
${ }^{1}$ Artigo elaborado com o apoio do Programa Operacional Ciência e Inovação 2010 (POCl 2010), co-financiado pelo Governo Português e pela União Europeia, através do Fundo Europeu para o Desenvolvimento Regional (FEDER), e da Fundação para a Ciência e Tecnologia (FCT); este artigo também tem o apoio da FCT através de uma Bolsa de Doutoramento Individual.

${ }^{2}$ Licenciada em Ciências da Comunicação (FCSH - Universidade Nova de Lisboa), Mestrado em Som e Imagem (Escola das Artes da Universidade Católica Portuguesa - UCP) e Pesquisadora do Centro de Investigação em Ciências e Tecnologias das Artes (UCP). Prepara uma tese de doutoramento sobre as adaptações televisivas de romances de Eça de Queirós. É também professora do Instituto Politécnico de Viseu e Bolseira de Doutoramento da Fundação para a Ciência e a Tecnologia. filomena@esev.ipv.pt
} 


\section{Introdução}

Se hoje, em termos internacionais, não é possível passar ao lado da questão televisiva, sendo a tele-visão motivo de «reflexão filosófica» (SANTOS, 2000: 121), o caso português também não é excepção, motivando análises e investigações ${ }^{3}$ que embora relativamente recentes, procuram reflectir sobre a «caixa que mudou o mundo» (WOLTON, 2000: 55) sob vários pontos de vista, como sejam o módulo cognitivo televisivo, os efeitos socioculturais, as políticas de programação e os aspectos económicos, políticos ou tecnológicos. Este interesse resulta, como facilmente se compreende, da «omnipotência e omnipresença da televisão» (VARA, 2002: 29) na sociedade portuguesa e do facto da televisão em Portugal ter adquirido maior visibilidade nos últimos quinze anos, sobretudo devido ao surgimento de canais privados (CUNHA, 2008). Por outro lado, inserindo-se num universo de transformação tecnológica dos média, a televisão portuguesa também não escapa à reflexão que daí resulta, procurando entender-se como se vai ajustar a televisão às novas plataformas de difusão (CARDOSO et al., 2006) ou que uso faz a egeneration dos media em Portugal (CARDOSO et al., 2007).

Neste sentido, procuramos neste artigo, num primeiro momento, traçar um mapa da evolução histórica da televisão em Portugal para, numa segunda etapa focarmos a nossa atenção na caracterização do sistema televisivo português, assim como nas políticas de programação. Paralelamente atentamos no consumo audiovisual em Portugal e nas tendências futuras de evolução do médium.

\section{Panorama histórico da televisão em Portugal}

Em Portugal os primeiros passos rumo à ideia de televisão são dados nos anos 50 do século XX, quando começam os estudos para a implantação de um serviço de televisão no território nacional e, finalmente, entre 4 e 30 de Setembro de 1956 iniciam-se as primeiras emissões experimentais da RTP (Radiotelevisão Portuguesa) a partir da feira popular de Lisboa ${ }^{4}$. Este período experimental

\footnotetext{
${ }^{3}$ Eduardo Torres (1998), João Santos (2000), João Cruz (2002), Manuel Pinto (2005), José Carlos Abrantes (2006), Cardoso et al. (2006), Cardoso (2007), Vasco Teves (2007), Cunha (2008), Rebelo et al. (2008), entre outros.

${ }^{4}$ A Radiotelevisão Portuguesa, SARL surge como uma sociedade anónima de responsabilidade limitada, com capital do Estado e de vários outros accionistas, entre os quais, várias emissoras de radiodifusão privadas e capitais particulares (como algumas instituições bancárias).
} 
caracteriza-se, em 1956, por apresentar uma programação baseada em filmes, telediscos e revistas filmadas (SANTOS, 2007: 84).

Após este período experimental, as emissões regulares ou oficiais da RTP, concessionária do serviço público de televisão, começam a partir do dia 7 de Março de 1957 (TEVES, 2007) ${ }^{5}$. Podemos, então, dizer, de acordo com terminologia de Umberto Eco (1993), que estamos num período de «paleotelevisão», uma época em que a televisão assume pretensões de instrução e distracção. No entender de Eduardo Prado Coelho (2006a) esta televisão tem poucas capacidades inventivas, limitando-se a transpor as formas existentes, como a informação e a ficção. E, neste âmbito, de acordo com Vasco Teves (2007) seria o teleteatro que se destacaria por a ser a "pedra de toque" da programação televisiva inicial. O primeiro teleteatro apresentado pela RTP, em 11 de Março de 1957, foi o Monólogo do Vaqueiro, realizado por Álvaro Benamor, mas muitos outros se seguiram como é o caso de $O$ Pedido de Casamento de Anton Tchekov (realizado por Artur Ramos em 25 de Março 1957) ou A Morgadinha de Vale d'Amores de Camilo Castelo Banco (realizado por Herlânder Peyroteo em 25 de Junho 1957) ${ }^{6}$. Para além disso, nesta fase inicial da televisão portuguesa estamos perante um serviço de televisão de monopólio Estatal, que predomina até ao início da década de 90 do século XX, altura em que se abre a actividade de televisão à iniciativa privada. Verificamos, também, que só nos finais dos anos 60 do século XX é que a emissão televisiva se processa a nível nacional, surgindo o segundo canal da Radiotelevisão Portuguesa, a RTP2, em 25 de Dezembro de 1968. Nos anos 60 há ainda a destacar a realização da primeira transmissão em directo do estrangeiro ${ }^{7}$, bem como as emissões transcontinentais em directo permitidas pelos satélites Telstar (1964) e Early Bird (1965).

Avançando uma década, constatamos que os anos 70 do século $X X$ da televisão portuguesa, altura em que faz vinte anos, são marcados pela transmissão da primeira telenovela brasileira, a Gabriela, e pelo primeiro concurso televisivo inteiramente nacional $A$ Visita da Cornélia, conteúdos que viriam a ficar na história da televisão em Portugal. Este momento é de tal forma importante, que Isabel

\footnotetext{
5 In http://ww2.rtp.pt/50anos/50Anos/Livro/DecadaDe50/AsEmissoesRegulares/ (Consultado em: 2009/07/06; 16h).

${ }^{6}$ In http://213.58.135.110/50anos/50Anos/Livro/DecadaDe50/AsEmissoesRegulares/Pag5\# (Consultado em: 2009/07/06; 16h).

${ }^{7}$ Com a primeira reportagem do encontro de hóquei em patins Espanha-Portugal a partir de Madrid em 15 de Maio de 1960 (Teves, 2007) In http://213.58.135.110/50anos/50Anos/Livro/DecadaDe60/RTPAos10Anos/Pag4\# (Consultado em: 2009/07/06; 16h).
} 
Cunha (s.d.) ${ }^{8}$ considera que estes dois programas marcaram uma viragem na televisão em Portugal, dando origem a uma sociedade focalizada no consumo mediático, sobretudo televisivo, que se mantém até hoje (REBELO et al., 2008). Igualmente relevante, ainda nos anos 70 , é o início das emissões regulares na Madeira (RTP Madeira, a 6 de Agosto de 1972) e nos Açores (RTP Açores, a 10 de Agosto de 1975). De observar, também nesta época, que a televisão nacional se manteve praticamente inalterada até 1974 (SANTOS, 2007: 85), altura em que se dá a mudança de regime político com a Revolução de 25 de Abril de 1974 e em que, após ocupação militar, se verifica a nacionalização da RTP (CÁDIMA, 1999: 31) .

O início da década de 80 do século XX é marcado pelo começo das emissões a cores (em 7 de Março de 1980) e testemunha ainda o surgimento das primeiras telenovelas portuguesas, que despontam com Vila Faia em $1982^{10}$. Este acontecimento vem acentuar o gosto do público português pelo formato telenovela, tendência que já vinha sendo confirmada pela constante presença das produções brasileiras nos ecrãs de televisão portugueses.

Deste modo, seguindo um caminho de evolução histórica, e de acordo com a perspectiva de Rogério Santos (2007: 86), é de salientar que «na segunda metade da década de 80 e anos seguintes assistir-se-ia a uma profunda mudança na área dos media em Portugal». Assim, a par de preocupações com os níveis de audiências, evidenciam-se, nesta altura, necessidades de reorganização que culminam na segunda revisão constitucional de 1989, o que vem permitir o fim de vários anos de monopólio estatal e a abertura da actividade de televisão ao sector privado (CÁDIMA, 1999: 32). Como facilmente se compreende, este momento assinala uma viragem marcante no sistema televisivo português e faz com que a televisão adquira uma nova dimensão na sociedade portuguesa (CUNHA, 2008: 6).

Sendo assim, assistimos nos anos 90 do século $\mathrm{XX}$, ao aparecimento de dois canais de televisão privados em Portugal: a SIC (Sociedade Independente de Televisão), que começou a operar em 6 de Outubro de 1992 e a TVI (Televisão Independente), que realizou a sua primeira emissão em 20 de Fevereiro de 1993. Igualmente relevante, na década de 1990, é o arranque das emissões regulares da RTP Internacional, em 10 de Junho de 1992, e a assinatura dos contratos de

\footnotetext{
${ }^{8}$ In http://www.bocc.ubi.pt/pag/cunha-isabel-ferin-revolucao-grabriela.pdf, pp.3-4 (Consultado em: 2009/07/02; 17h)

${ }^{9}$ O Decreto-Lei no $674-\mathrm{D} / 75$, de 2 de Dezembro de 1975, nacionaliza as posições sociais no capital da RTP que não pertenciam ao Estado, surgindo, assim, a empresa pública RTP - Radiotelevisão Portuguesa, EP.

${ }^{10} \mathrm{O}$ remake desta telenovela estreou no canal 1 da RTP em Março de 2008.
} 
concessão do serviço público de televisão, entre o Governo e a RTP, primeiro em 1993 e depois em 1996, que permitem assegurar uma televisão de serviço público ${ }^{11}$. Outro acontecimento que marca os anos 90 do século XX em Portugal é a introdução da televisão por cabo em 1994, permitindo assim um ampliar da oferta de serviços de televisão em território nacional. Surgem, deste modo, canais temáticos como o Canal Panda (1996) ou a Sport TV (1998), entre outros. Neste sentido e, caminhando para o final da década de 1990, é também de sublinhar o aparecimento, em 7 de Março de 1997, da RTP África, uma emissão vocacionada para os países africanos de expressão portuguesa, bem como da SIC Internacional, em Setembro do mesmo ano.

Em termos gerais de programação, os anos 90 do século $X X$ são marcados, para além de espaços informativos, por concursos, comédias televisivas, entretenimento, séries e telenovelas. Esta é, todavia, uma altura conturbada para a televisão em Portugal ${ }^{12}$, que viria a culminar, a partir de 2000, numa alteração do panorama televisivo. Com efeito, a RTP, acumulando prejuízos vai, entretanto, ser objecto de reestruturação em 2002-03 (CUNHA e BURNAY, 2006: 3), a TVI, da Media Capital, passa a ser controlada pelos espanhóis do Grupo Prisa e a SIC, pertença do Grupo Impresa, procura recuperar o papel de liderança que perdera.

Recentemente, em 7 de Março de 2007, comemoraram-se os cinquenta anos de existência de emissões televisivas regulares em Portugal e à data de 2008, já se encontrava em preparação a implementação da televisão digital terrestre, que prevê o surgimento de um novo canal generalista em sinal aberto. Em 22 de Janeiro de 2009 terminou o prazo para a apresentação de candidaturas ao $5^{\circ}$ canal da Televisão Digital Terrestre (TDT) - Canal generalista de acesso livre transmitido em TDT com arranque previsto para 2010, tendo-se apresentado a concurso dois candidatos: a Zon Multimédia e a Telecinco, S.A. Porém, ambas as candidaturas foram rejeitadas pelo organismo regulador dos média em Portugal (ERC). Em 29 de Abril de 2009 iniciaram-se as emissões em TDT no território português, devendo a cobertura ser alargada gradualmente a todo o país até 2011, para que, em 2012, a

\footnotetext{
${ }^{11}$ A RTP/ Radiotelevisão Portuguesa, S.A.: sociedade anónima de capitais unicamente públicos. No entanto, Cádima (1999) não concorda com os termos estabelecidos nestas concessões, considerando que se tratam de aspectos que não se enquadram naquilo que se define como serviço público de televisão. Estabelece o autor que «o serviço público de televisão identifica-se prioritariamente nos conteúdos da programação e não por imputação genérica e indeterminada de custos de exploração, manutenção ou mesmo difusão» (Cádima, 1999: 32).

12 Perturbação que se caracteriza, segundo Cunha e Burnay (2006: 3) pela crise da nova economia, onde o grupo detentor da SIC tinha investido os lucros do canal; pela transição da propriedade da TVI para o Grupo Media Capital e pelo início da contenção de gastos do Estado Português com a RTP.
} 
teledifusão analógica esteja desligada em todos os países da União Europeia. De notar, fundamentando-nos em Célia Quico (s.d.), que «a transição do analógico para o digital permite não só a transmissão de mais canais digitais na mesma largura de banda ocupada por um só canal analógico, como também permite a difusão de serviços digitais e interactivos ${ }^{13}$, a próxima etapa de uma história de evolução contínua do panorama audiovisual português.

Importa acrescentar que, ainda em 2009 (26 de Fevereiro), começou a operar mais um canal informativo temático português na grelha da TV Cabo: o TVI24, um espaço com informação televisiva durante 24 horas por dia, que se vem juntar à RTPN (a emitir desde 31 de Maio de 2001) e à SIC Notícias (em emissão desde 8 de Janeiro de 2001). Este é, portanto, mais um momento que vale a pena assinalar num universo televisivo que se prevê que vá continuar em transformação num futuro próximo (CARDOSO, 2006).

\section{Caracterização do sistema televisivo português}

O sistema de televisão em Portugal, após ter passado por um período de monopólio público das emissões e na sequência de profundas transformações tecnológicas, económicas, político-legais e sociais (TRAQUINA, 1997: 16), entrou definitivamente na era concorrencial com o surgimento de outras opções. É, por conseguinte, a fase da neotelevisão que Santos (2007: 80) caracteriza como sendo a época da "desregulamentação», que transforma as audiências em «público-alvo», e cujo financiamento da actividade televisiva é efectuado «basicamente através da publicidade». Coelho (2006a) considera que o aspecto fundamental desta fase é a fragmentação do fenómeno televisivo.

Deste modo, o panorama audiovisual português oferece agora aos telespectadores um sistema televisivo que se caracteriza pela coexistência de televisões públicas e privadas em sinal aberto $^{14}$, pela existência de televisão por cabo com possibilidade de acesso a diversos canais, entre os quais se incluem os temáticos, e acesso a múltiplas emissões televisivas disponibilizadas por satélite através de antenas parabólicas, verificando-se que a televisão se tornou mais fragmentada. Constata-se também a disponibilização de conteúdos televisivos pelas

\footnotetext{
${ }^{13}$ In http://www.bocc.ubi.pt/pag/quico-celia-jogos-de-computador-televisao-digital.pdf (Consultado em: 2009/02/11; $12 \mathrm{~h}$ ), p. 8.

${ }^{14}$ Vários canais generalistas de acesso nacional gratuito, públicos e privados: a RTP1, a RTP2 e os privados SIC e TVI.
} 
plataformas online ${ }^{15}$. Por outro lado, assiste-se à emergência de grandes grupos de comunicação que operam no sentido da concentração dos média e emergem novos meios que dividem a atenção do espectador para outro tipo de ecrãs, como é o caso dos canais regionais na Internet (dos quais podemos nomear 'Minho actual TV' e 'TV Beja') e os canais de TV Móvel, como a RTP Mobile, que se caracterizam por serem canais específicos para plataformas móveis. Entramos, desta forma, numa fase de «pós- televisão» (SANTOS, 2007: 80), ou «a época dos pequenos canais especializados e de audiência reduzida, hiperfragmentados, onde o espectador quase atinge a possibilidade de ser programador daquilo que vê» (Idem, Ibidem).

Gustavo Cardoso e Rita Espanha (2007: 2), referindo-se, de uma forma geral, ao consumo do audiovisual em Portugal, constatam que este está em plena mutação, sendo esta transformação motivada por novas possibilidades de consumo, visionamento e interacção proporcionada pelos novos média. O consumo mediático actual caracteriza-se essencialmente pela personalização, privatização e interactividade (CARDOSO e ESPANHA, 2007: 4). Luís Loureiro (2008: 330) fala em egocasting ${ }^{16}$ para se referir a uma nova fase de convergência e hipermodernidade em que a televisão tende a integrar características dos meios interactivos e do consumo da Internet e onde o indivíduo se transforma em produtor, receptor e utilizador. O autor dá o exemplo do lançamento em Portugal da marca Meo, em Abril de 2008, pela Portugal Telecom (PT) que «oferece um conjunto de serviços integrados de televisão» (LOUREIRO, 2008: 330) ${ }^{17}$. Neste sentido, Loureiro (2008: 331) destaca, na senda de Carlos Scolari (2006), que a televisão actual caminha no sentido da hipertelevisão, uma evolução capaz de conjugar «a televisão generalista, geradora de comunhão social, participação democrática e identidade partilhada» e outras referências que permitem aos indivíduos «desenhar um caminho totalmente autónomo, independente e individualizado».

Sendo assim, apostando numa linha mais comunicacional do que tecnológica, também a televisão generalista de sinal aberto tende a diversificar a sua oferta, procurando acompanhar a fragmentação de interesses, assim como a

\footnotetext{
${ }^{15}$ Como é o caso da RTP com emissões televisivas acessíveis em www.rtp.pt, da SIC em http://sic.aeiou.pt/online/homepage ou da TVI em http://www.tvi.iol.pt/home.html.

${ }^{16}$ Conceito de Christine Rosen (2005) referindo-se a «um mundo onde exercemos um controlo sem precedentes sobre o que vemos e o que ouvimos» (apud Loureiro, 2008: 327).

17 «À televisão distribuída sobre o protocolo Internet (IPTV) e de conteúdos para outras plataformas como o telemóvel, a Meo juntou a oferta por satélite que inclui também possibilidades interactivas como a gravação para posterior visionamento, a "pausa" de programas, a catch up TV, que permite ver programas cuja gravação não foi solicitada pelo utilizador e a definição de programas favoritos para a construção de uma grelha personalizada, além de prometer conteúdos em alta definição» (Loureiro, 2008: 330-31).
} 
«individualização na relação com os media» (CARDOSO et al., 2007: 398). Portanto, num ambiente de forte concorrência, motivado sobretudo pela guerra de audiências entre os operadores de televisão, há uma alteração substancial da oferta televisiva, ou seja, há um aumento do número de programas e possibilidades de acesso, que devem atrair o máximo de indivíduos.

Com efeito, desde que começou a operar, em 1993, até ao ano 2000, a programação da TVI foi sobretudo importada. Com a entrada no novo milénio, o canal mudou de estratégia e começou a apresentar mais ficção nacional, como telenovelas ou séries. Por outro lado, esta estação privada investiu igualmente em programas infantis, mais informativos e reality shows. Actualmente a produção portuguesa, sobretudo de telenovelas, assume especial relevância na TVI, canal que detém a preferência dos telespectadores portugueses.

Em relação à SIC, de assinalar que o estabelecimento de um acordo de exclusividade entre este operador privado e a Rede Globo fez com que, até 1999, a grelha de programas da SIC fosse, em grande parte, composta por telenovelas brasileiras. Em termos de produção nacional a grande aposta da SIC começou com a apresentação de um conjunto de reality shows, porém rapidamente o canal começou a diversificar os géneros, compondo um alinhamento de produtos que vão desde sitcoms, talk shows, informativos, telenovelas, concursos, séries e algumas mini-séries.

No que concerne à televisão pública portuguesa (RTP), para além dos diversos géneros de produção nacional que já referimos para os outros canais privados, como os espaços informativos, concursos, comédias televisivas, entretenimento, séries e telenovelas, a RTP destaca-se também pela apresentação de mini-séries, sobretudo de época ${ }^{18}$.

No entanto, o que nos parece interessante observar é que, apesar do impacto das novas Tecnologias da Informação e Comunicação na sociedade portuguesa, a televisão não perdeu a sua importância (CARDOSO, 2008; QUICO, 2008; REBELO et al., 2008). Aliás, comparativamente com a realidade dos valores europeus, podemos constatar que o tempo médio de visionamento de televisão em Portugal «reflecte o forte peso da televisão nas práticas mediáticas dos portugueses» (CARDOSO, 2008: 33). A verdade é que a televisão é o médium mais utilizado em

${ }^{18}$ A título de exemplo podemos referir: O Processo dos Távoras (2001), A Ferreirinha (2004), João Semana (2005), Bocage (2006), Quando os Lobos Uivam (2006), Nome de Código: Sintra (2007) ou O Dia do Regicídio (2008). 
Portugal (REBELO et al., 2008: 67) e também entre as camadas mais jovens (dos 8 aos 18 anos), de acordo com dados de Cardoso et al. (2007: 413). Num sentido idêntico, Quico (2008), procurando perceber se está eminente a emergência de uma cultura participativa, reforça esta tendência, salientando que dos 77 jovens portugueses que inquiriu (entre os 12 e os 18 anos) a maioria vê televisão todos os dias, enquanto que apenas metade dos inquiridos reportou usar a Internet diariamente, o que, segundo a autora, "contrasta de forma significativa com a frequência de uso da televisão por parte deste grupo de jovens» (QUICO, 2008: 88). De observar, ainda, segundo dados do relatório A Sociedade da Informação em Portugal 2008, da responsabilidade da UMIC - Agencia para a Sociedade do Conhecimento, que a grande maioria dos utilizadores da Internet em Portugal situase nas faixas etárias entre os 16 e os 24 anos e dos 24 aos 34 anos, incidindo as principais utilizações sobre correio electrónico (85\%) e pesquisa de informação sobre bens e serviços $(81 \%)$. No que diz respeito aos aumentos da utilização da Internet entre 2005 e 2008, estes evidenciam-se nos contactos por videoconferência, desenvolvimento de blogs e informações sobre a saúde. O que nos parece que não substitui os usos que se fazem da televisão.

Com efeito, entre os anos de 1999 e 2007, o que se tem verificado em Portugal é uma série de mudanças e disputas de posições entre a RTP, a SIC, a TVI e o Cabo e outros canais, tendo a TVI, em 2001, conquistado o primeiro lugar, seguida pela SIC e pela RTP1 (CARDOSO, 2008). Segundo dados da Marktest ${ }^{19}$, em 2008 a TVI consolidou a liderança das audiências televisivas em todos os meses do ano, estando a SIC e a RTP1 bastante próximas, disputando consecutivamente o segundo e o terceiro lugar. Os canais por cabo surgem posicionados a seguir aos três principais canais generalistas portugueses em termos de consumo televisivo e logo a seguir está a RTP2.

No início de 2009, de acordo com a revista Noticias TV (2009: 74) este panorama persiste, ou seja, «A TVI manteve a sua performance e continua a ser a estação preferida dos portugueses», a SIC estabilizou no segundo lugar e a RTP1 ocupa a terceira posição ${ }^{20}$.

\footnotetext{
${ }^{19}$ A Marktest Audimetria é a empresa do grupo Marktest responsável pela recolha da informação de audiências de televisão, em Portugal.

${ }^{20} \mathrm{Em}$ Junho de 2009, tendo por base dados da Marktest Audimetria/ MediaMonitor, as audiências de televisão em Portugal distribuíam-se da seguinte forma: Decorridos seis meses desde o início do ano a TVI continua a liderar o share mensal com $29.0 \%$. A segunda posição voltou para a SIC que em Junho alcançou 23.5\%, em troca com a RTP1 que ficou com $22.2 \%$ de share. O "canal" Cabo/outros obteve 19.0\%. Finalmente a RTP2 surge com 6.1\% de share. (Informação consultada em: http://www.mediamonitor.pt/ 2009/07/10; 11h).
} 
Em termos de conteúdos, entre Janeiro de 2008 e Setembro do mesmo ano, os canais generalistas a operarem em Portugal emitiram 13442 horas de programas portugueses ${ }^{21}$, sendo de destacar que foi a ficção o género que ocupou a maior parte da programação, bem como representou também o maior consumo televisivo ${ }^{22}$. Prevê-se que até 2010 o consumo televisivo aumente, sobretudo no que diz respeito ao género ficção e a nível da produção nacional (CARDOSO, 2006). A confirmar esta tendência estão as preferências dos jovens portugueses pela produção nacional, sobretudo por telenovelas e séries de humor e ficção (CARDOSO et al., 2007: 399). Também o estudo da Entidade reguladora da Comunicação Social - ERC (REBELO et al., 2008) faz sobressair que os programas mais vistos pelos telespectadores portugueses são as telenovelas, filmes e séries, em especial nos canais TVI e SIC, dirigindo-se estas preferências nos espectadores mais assíduos da RTP1 para depois do futebol e a seguir aos concursos (REBELO et al., 2008: 84-85). Em Janeiro de 2009 as telenovelas portuguesas da TVI continuavam a ser dos programas mais vistos (Notícias TV, 2009: 74), facto que se mantém em Junho deste mesmo ano.

Deste modo, a paisagem televisiva generalista portuguesa caracteriza-se fundamentalmente pela primazia dada à função de entretenimento, com um acréscimo substancial do número de horas de ficção, talk shows e telenovelas (TRAQUINA, 1997: 18). Também os dados do Anuário da Comunicação 2006-07 apontam neste sentido, enfatizando que «Entre o leque de ofertas das televisões portuguesas generalistas de sinal aberto, destaca-se o maior peso da programação de entretenimento e divertimento, de informação, dos programas de ficção e da publicidade» (CARDOSO, 2008: 33).

Em termos gerais de programação, podemos constatar que a política televisiva portuguesa, apesar de apostar claramente na produção nacional, apresenta também variada programação estrangeira importada, sobretudo dos Estados Unidos e do Brasil, mas também de outros países. A este propósito, convém não esquecer que a Lei da Televisão (№ 27/ 2007) acentua a necessidade dos operadores televisivos deverem dar primazia a uma oferta de programas de expressão originária portuguesa ${ }^{23}$. E de facto, segundo testemunho de Cunha e

\footnotetext{
${ }^{21}$ In http://www.marktest.com/wap/a/n/id 1201.aspx (Consultado em: 2009/06/11; 15h).

22 In http://www.marktest.com/wap/a/n/id 114f.aspx (Consultado em: 2009/06/11; 15h).

${ }^{23}$ Pode ler-se na alínea 1, do artigo 25 da Lei da Televisão: «Os operadores de distribuição devem, na ordenação e apresentação da respectiva oferta televisiva, atribuir prioridade, sucessivamente, aos serviços de programas televisivos de
} 
Catarina Burnay (2006), o que se verificou em Portugal, principalmente depois da entrada em funcionamento dos canais privados, foi uma maior aposta na produção nacional, sobretudo a partir do ano 2000.

\section{Considerações finais}

Verificámos que ao longo dos seus cinquenta e dois anos de emissões regulares, a televisão generalista portuguesa sofreu um enorme processo de evolução que culmina, em 2009, com a substituição gradual da teledifusão analógica pela nova tecnologia de difusão em sinal digital (TDT). Trata-se, efectivamente, de uma longa história que deu origem ao surgimento de diversos canais, cuja oferta variada premeia o telespectador com uma panóplia de programas que satisfazem inúmeras individualidades, indo de encontro ao pluralismo essencial numa vivência em democracia.

Para além disso, num ambiente de forte convergência tecnológica, a televisão procura adaptar-se aos novos hábitos de consumo de um público espectador que dispersa a atenção para outro tipo de ecrãs, como o computador e o telemóvel. Por conseguinte, não deixa de ser verdade que apesar da televisão continuar a marcar presença nos lares portugueses, o seu consumo entre os mais novos assume novos moldes, sendo cada vez mais multi-tarefa (CARDOSO et al., 2007: 412). Por esta razão, verifica-se também uma adaptação da televisão aos novos tempos, com a integração de conteúdos na Internet e oferta de interactividade a curto prazo.

Assim, no que diz respeito à paisagem mediática portuguesa, o estudo de Cardoso et al. (2007: 414) não deixa margem para dúvidas: «a importância da televisão, hoje em dia, é incontornável» e, apesar da expansão verificada nos últimos anos em Portugal dos canais temáticos, o que se verifica é que as emissoras generalistas "continuam em lugares cimeiros em termos de preferências» (CARDOSO et al., 2007: 399), e isto também entre os mais jovens, o que nos parece que é bastante significativo.

No entanto, prevê-se que num futuro próximo (até 2012 segundo directrizes da União Europeia) a Televisão Digital Terrestre permita aos telespectadores portugueses mais qualidade, maior quantidade de canais e mais variedade de 
programas, havendo, todavia, necessidade da televisão generalista se "reinventar" para responder aos desafios emergentes do novo mundo da tecnologia digital.

\section{Referências Bibliográficas}

ABRANTES, José Carlos (Coord). Ecrãs em Mudança: Dos jovens na Internet ao Provedor da Televisão. Lisboa: Livros Horizonte, 2006.

CÁDIMA, Francisco Rui. Desafios dos Novos Media, a nova ordem política e comunicacional. Lisboa: Editorial Notícias, 1999.

CARDOSO, Luís Landerset (coord). Portugal Audiovisual - Base de dados Intersectorial da Convergência audiovisual/ Multimédia em Portugal. Lisboa: Obercom. 2006.

CARDOSO, Gustavo (coord). E-Generation: Os Usos dos Media Pelas Crianças e Jovens em Portugal. Lisboa: CIES-ISCTE, 2007.

CARDOSO, Gustavo; ESPANHA, Rita. Cinema em ecrãs privados, múltiplos e personalizados. Transformação nos consumos cinematográficos. Lisboa: Obercom, 2007.

CARDOSO, Gustavo (coord). Anuário da Comunicação 2006-2007. Lisboa: Obercom, 2008.

COELHO, Eduardo Prado. Para onde vai a televisão? Jornal Público, Edição de 22 de Setembro de 2006a.

COELHO, Eduardo Prado. Para onde vai a televisão?(2) Jornal Público, Edição de 29 de Setembro de 2006b.

CRUZ, João Cardoso da. Introdução ao Estudo da Comunicação. Lisboa: Universidade Técnica de Lisboa, 2002.

CUNHA, Isabel Ferin. Ficção Televisiva e Entretenimento. Actas do XXXI Congresso Brasileiro de Ciências da Comunicação. Natal: Brasil, Setembro de 2008 (CD-ROM).

CUNHA, Isabel Ferin; BURNAY, Catarina. Ficção Televisiva em Portugal. Biblioteca on-line de Ciências da Comunicação. Covilhã: Universidade da Beira Interior, pp. 1-17, 2006. Disponível em: http://www.bocc.ubi.pt/pag/ferin-isabelburnay-catarina-ficcao-televisiva-portugal.pdf Acesso em: 2008/02/20; $14 \mathrm{~h}$.

ECO, Umberto. Viagem na Irrealidade Quotidiana. Lisboa: Difel, 1993.

ECO, Umberto. Apocalípticos e integrados. São Paulo: Perspectiva, 1979. 
LOUREIRO, Luís Miguel. Convergência e hipermodernidade: emerge a TV do ego. Revista PRISMA.COM. Porto: Universidade do Porto, no 7, pp. 315-338, Dezembro de 2008.

PINTO, Manuel. Televisão e Cidadania. Lisboa: Campo das Letras, 2005.

QUICO, Célia. Participação nos media e os jovens dos 12 aos 18 anos: estudo de avaliação de um formato 'cross-media'. Revista PRISMA.COM. Porto: Universidade do Porto, № 6, pp. 75-111, Julho de 2008.

QUICO, Célia. "It came from outer space": jogos de computador invadem programação e serviços de televisão digital. Biblioteca on-line de Ciências da Comunicação. Covilhã: Universidade da Beira Interior, pp. 1-20. Disponível em: http://www.bocc.ubi.pt/pag/quico-celia-jogos-de-computador-televisao-digital.pdf Acesso em: 2009/02/11; $12 \mathrm{~h}$.

REBELO, José (coord). Os Públicos dos Meios de Comunicação Social Portugueses. Lisboa: Entidade Reguladora para a Comunicação Social, 2008.

SANTOS, João de Almeida. Homo Zappiens: o feitiço da televisão. Lisboa: Editorial Notícias, 2000.

SANTOS, Rogério. Indústrias Culturais: Imagens, Valores e Consumos. Lisboa: Edições 70, 2007.

TEVES, Vasco Hogan. RTP 50 anos - História da Televisão em Portugal. Lisboa: RTP, 2007.

TEVES, Vasco Hogan. RTP 50 anos de história: 1957-2007 Disponível em: http://ww2.rtp.pt/50anos/50Anos/Livro/ Acesso em: 2007/12/06; 16h.

TORRES, Eduardo Cintra. Ler Televisão. Lisboa: Celta, 1998.

TRAQUINA, Nelson. Big Show Media .Lisboa: Editorial Notícias, 1997.

VARA, Armando. Sessão de Abertura do Seminário Internacional sobre Media, Jornalismo e Democracia. In Vários. Media, Jornalismo e Democracia. Lisboa: Livros Horizonte, 2002, pp. 27-30.

WOLTON, Dominique. E depois da Internet? Lisboa: Difel, 2000.

\section{Revistas}

Noticias TV, ํo 52, 09 a 15 de Janeiro 2009, p. 74. (Revista de Televisão/ parte integrante do jornal Diário de Notícias no 51048 de 09 Janeiro 2009). 